\title{
LANDSCAPE SENSITIVITY ANALYSIS AS AN ECOLOGICAL KEY: THE CASE OF DUZCE, TURKEY
}

\author{
KARADAĞ, A. A.* - ŞENIK, B. \\ Department of Landscape Architecture, Faculty of Forestry, Düzce University, Konuralp \\ Campus, 81620 Duzce, Turkey \\ *Corresponding author \\ e-mail:ayferkaradag@duzce.edu.tr \\ (Received $2^{\text {nd }}$ Jun 2019; accepted $10^{\text {th }}$ Sep 2019)
}

\begin{abstract}
Landscape sensitivity is one of the ways that give us the opportunity to exhibit ecology-based approaches to the world we live in. Landscape sensitivity refers to areas where landscape is sensitive to natural or human-based pressures. This study aims to develop a model for revealing and mapping the landscape sensitivity of Duzce province in Turkey. The model was developed by evaluating four parameters (ecologic process). These are erosion risk, landslide susceptibility, water infiltration and habitat fragmentation. Within the scope of the study, sensitivity data related to each parameter has first been formed within the framework of expert opinions and then all data has been analyzed by ArcGIS 9.3 software and a Duzce Province Landscape Sensitivity Map has been produced. When the landscape sensitivity map obtained within the scope of the model is evaluated, it is seen that the sensitivity in $38.6 \%$ of the area is low while it is medium with $30.6 \%$, very low with $21.7 \%$, high with $8.2 \%$ and very high with $8.2 \%$. These findings are easily visualized on the map. As a result, the landscape sensitivity map produced is a data that is compatible with ecological principles, produced by scientific methods, compatible with technological tools and can be integrated with similar analyses. In addition it is an important element to develop ecological based decisions related to the space. Therefore, its usage as a basis map for spatial planning is a need beyond desire.
\end{abstract}

Keywords: ecological sensitivity, vulnerability, risk analysis, suitability analysis, land use decision, landscape planning

\section{Introduction}

The coexistence of nature and man is an existential necessity. Indeed, there is no other space in the known universe where human beings can survive. On the other hand, nature has no such obligation. For nature can realize its cycle on its own. Such that, the quite short history of mankind in the world is the clearest indication of our need for nature and not its need for us. In the simplest sense, man is born and raised within nature; he grows up and builds his culture and civilization there. However, human beings' disposition on nature varies according to historical periods (İlboğa and Aygül, 2015). This differentiation has been rapidly moving towards a humanistic approach that sees nature as an object exploitable for its own interests and commodifies it. Scientists who realized this strived to reveal the discomforts caused by this commoditization process and to identify its sensitivity to solve the problems. Landscape sensitivity is one of the studies conducted in this context.

The landscapes arose from the unity of man and nature. The landscape is a combination of rocks, surface deposits, soils, plants, animals, people, etc. together with the earth itself, and each of these is a component of the landscape. The landscapes do not only contain objects, they also include dynamic earth surface systems. In this context, they are energy and material stores maintained with growth, decay, flow and transformation processes. The landscapes exhibit spatial mosaics forming a "complex 
combination" at different characters and scales on the earth's surface (Thomas, 2001). In this context, the landscape is a heterogeneous land area consisting of similarly replicated and interrelated ecosystem clusters, i.e. habitat patches (Forman and Godron, 1986; Dunning et al., 1992; Turner et al., 2001; Boström et al., 2011). While maintaining growth, decay, flow and transformation processes of landscaping, the landscape is also dynamical earth surface systems containing not only objects but also energy and material stores (Thomas, 2001). The landscape which consists of many superimposed environments or components is the semiotic interface between sources and organisms, and it is shaped by ecological processes (Farina, 2001, 2008; Farina and Pieretti, 2012). In fact, landscaping refers to two natural systems (physical and biological) and processes that constitute this system. Physical systems are composed of landform, surface deposits, rock components and are formed as a result of processes such as rock erosion and sediment transportation etc. Biological systems are composed of plants, animals and people, and have many ecological processes. Soil is the other component of landscape which these two systems closely interact with. In short, landscaping is an area on which action, interaction and various relationships between natural and/or cultural resources take place (Demir, 2019). Therefore, it is a dynamic and multidimensional concept.

With its components and ecological processes, the landscape has become key to defining the relationship between nature and human beings, and the common evolution between natural and human processes (Mazzino and Burlando, 2010). For, the landscape is the product of a long history of evolution that reflects the interactions of landscape, geology, topography, climate, geomorphologic processes and their transformations over time (Gordon and Sutherland, 1993). All aspects of landscaping (ecological, economic, social) also arise with historical processes (Turner, 2018). This process is in fact related to the history of Quaternary. The history of the Quaternary has evidence related to the occurrence rate of natural processes (especially geomorphologic processes) and plant communities' response to both climatic changes and improvements. Furthermore, this evidence provides information on the development of the natural environment before and after the human impact (Gordon and Sutherland, 1993). This information provides important clues to the understanding landscape formation and change. These clues can contribute to the identification of red lines related to human life in the landscape. As Usher (2001) argues, human is also a part of this landscape and as natural as plants, but due to its non-conscientious nature, it is necessary to determine its boundaries of movement in the landscape, to provide the nature with an opportunity to renew the nature and to ensure its sustainability. In this context, it is very important to determine the landscape sensitivity, in other words to determine the sensitive areas in the landscape. The result is an open system; any interference from outside may affect this structure. These effects on the landscape can be realized in such a way as to contribute to the sustainability of the landscape or change its very structure (Steffen et al., 2011; Lewis and Maslin, 2015).

Landscape sensitivity is not easy to define. It requires considering the main natural systems that determine the landscape, its structure and the processes that change these natural systems (Usher, 2001). Based on this idea, the concept comes from geomorphology (Miles, 2001). Biostasisve and rexistasis concepts used by Erhart in 1955 to define the transition from biogeochemical equilibrium to the conditions of erosion and clastic sedimentation that refer to the basic idea of landscape sensitivity concept. However, the "landscape sensitivity" concept was first used in 1979 by 
Brunsden and Thornes to help think about geomorphological systems and understand especially episodes of erosion and sedimentation (Thomas, 2001). The first definition of the concept of landscape sensitivity was as "landscape's capacity to absorb the effects of changes and disturbances." Since then, the meanings of landscape sensitivity have been constantly explored and developed (Chia et al., 2019). For example, landscape sensitivity is expressed as the ratio of change in a system in a landscape component. The higher the ratio is, the greater is the sensitivity (Usher, 2001). Due to perturbations in controlling environmental processes, landscape sensitivity is defined as conditional instability in the system with the possibility of a rapid and irreversible change. It has also been used to describe the response of landscape systems to perturbations at different time and spatial scales (Thomas, 2001). Landscape sensitivity was also defined as landscape's exposure to external stressors of the natural components of the landscape and thus, their capacity to change or to be affected or harmed (Aretano et al., 2015; Kesoretskikh et al., 2015).

Usually, there is a need for landscape sensitivity for three reasons. These include: (i) determining which environmental conditions require a major change in the landscape; (ii) identifying which parts of the landscape are affected in what proportions; (iii) demonstrating how long the transition of landscape features will be before the semiequilibrium state is reached (Knox, 2001). For, the landscape can give different responses to anthropogenic pressures or ecological processes. As stated by Brunsden, when a landscape is in a state of stability with respect to controlling environment and its minor perturbations, the change will be incremental and at rates that allow mutual readjustment between all the components of the landscape complex. But when instability results from increases in the magnitude and rate of stress applied to landscape components, a period of readjustment will take place, as the various subsystems respond by attempting to establish new equilibria. These equilibria will not be attained if the frequency of high magnitude events, enough to cause further disturbance, is greater than the 'relaxation time' of the system. The stability of ecosystems has been considered both in terms of their resistance to displacement by disturbing forces, and their ability to recover after disturbance (Thomas, 2001). At this point, it is important to distinguish between concepts of sustainability/adaptive capacity, resilience and vulnerability in understanding landscape sensitivity. Sustainability or adaptation capacity is the capacity of a system to withstand external influences/pressures, to manage the risks and effects, to respond to the challenges by developing effective approaches, and to adapt (Turner et al., 2003; Damiano et al., 2014; Kesoretskikh et al., 2015). Resilience is defined as the ability of a system to improve, reorganize and develop against stresses and disturbances (Aretano et al., 2015). Resilience can also be expressed as the capacity to adapt (Vaillant et al., 2016). Vulnerability is generally referred to as sensitive landscapes' exposure to the stressor and their inability to absorb the change and failure to adapt. In this context, vulnerability has three primary components: exposure to the stressor, sensitivity to a range of stressor variability, and resilience following exposure (Adger, 2006; Birkmann and Wisner, 2006; Golobič and Žaucer, 2010; Damiano et al., 2014; Aretano et al., 2015; Campbell et al., 2016; Vaillant et al., 2016; Menezes et al., 2018). In this context, low adaptation capacity and resilience increase the landscape sensitivity. High sensitivity and these areas' failure to adapt due to constant pressure causes vulnerability. Therefore, the relationship between sensitivity and vulnerability is very important in understanding the process. 
The aim of this study is to reveal the landscape sensitivity based on ecological processes and to identify the sensitive areas. In addition, the properties and importance of sensitivity maps are revealed.

\section{Materials and methods}

\section{Study case}

The study was conducted in Duzce province in the Black Sea region located in 64685.081-613754.468 and 572602.468-766623.408 UTM coordinates (ED-1950-utmzone $36 \mathrm{~N})$ (Fig. 1). The study area covers approximately $2487 \mathrm{~km}^{2}$ area, and this area constitutes $0.3 \%$ of Turkey (Tatar, 2003; Anonymous, 2019a). Water resources, vegetation cover, rich biodiversity and ecologically sensitive qualities were effective in determining the study area.

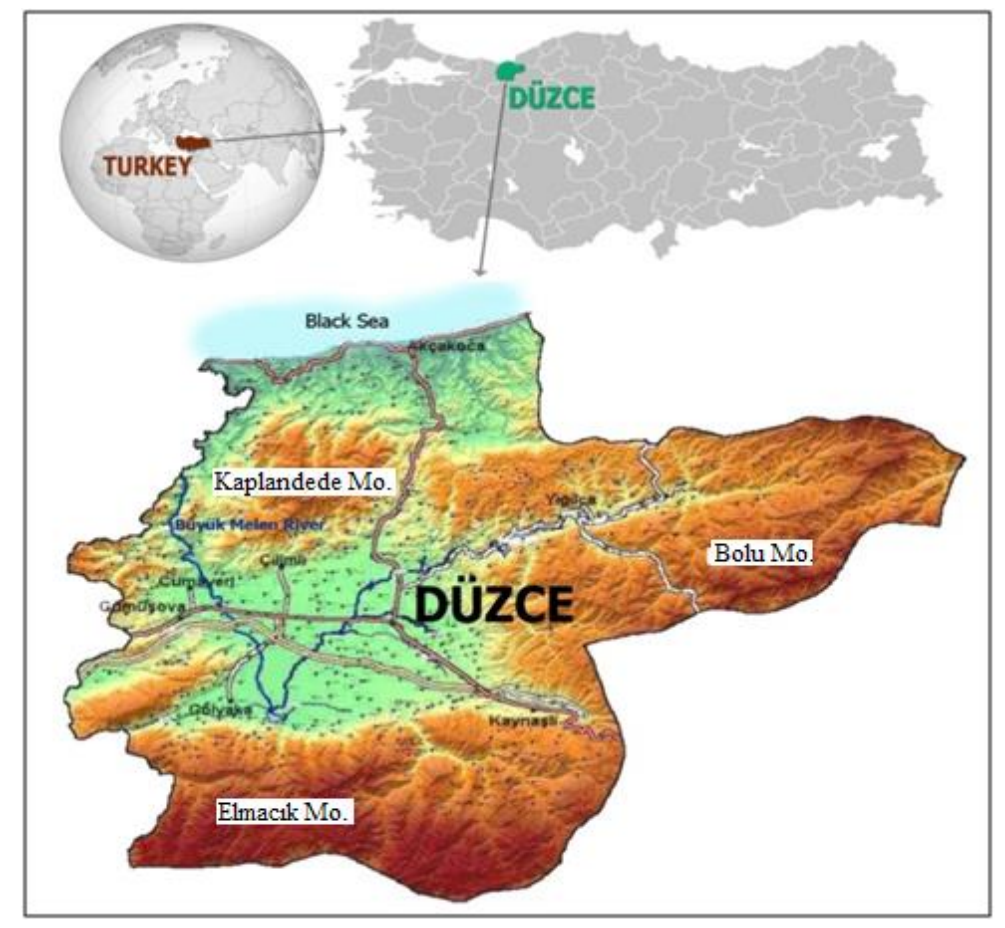

Figure 1. The location of the study area

The study area has a landscape view surrounded by the plain of Duzce near the south-west border and mountains in the north, south and east. Approximately $14.5 \%$ of the area is Duzce plain and its $85.5 \%$ is mountainous areas surrounding this plain. The mountain heights are 1388-1380 in the south and east, and they reach to the Black Sea as the heights reduce northward. The mountains are generally divided into deep valleys (Tatar, 2003). 64.2\% of the area has more than $20 \%$ slopes. Urbanization and settlements are concentrated in Duzce plain and other plains due to high slopes. The flat areas are located in the plateaus in the mountains, Duzce plain and Black Sea coasts (Anonymous, 2000). The area is located in North Anatolian Fault line, 1st-degree seismic zone. It has 22 various rock formations with different names such as sandstone, shale, conglomerate, siltstone, limestone, ophiolitic rocks, granite, gabbro, tuff, 
andesite, basalt, agglomerate, gneiss, metagranite, amphibolite, migmatite, marble, phyllite etc. Duzce plain is covered with thick and loose alluvium (Anonymous, 2002; Tatar, 2003). The hydrological structure of the area consists of 6 large streams, ranging in length from $4.5 \mathrm{~km}$ to $17 \mathrm{~km}$; 7 natural lakes, reservoirs, groundwater and geothermal resources (Anonymous, 2019a). 79.8\% of the area is in VI., VII. and VIII. degree land use capability class which have limited agricultural potential. Most of the fertile agricultural land is located in Duzce plain (Anonymous, 2010). The study area is located in the flora of Euxine and Xsero-Euxine transition zone and the vegetation cover is very rich. In the area, there are 14 taxon rare plants located under 11 families. There are also 66 endemic species. 5 of them are in critically endangered (CR), 2 in endangered (EN), 3 in vulnerable (VU), 12 in near threat (NT) and 44 in the least concern (LC) category. The area is ranked 15th in terms of its forest density. In addition, there is one protection area (430 ha), four nature parks ( $340.71 \mathrm{ha}), 4$ natural monuments (10 ha) and 3 wildlife development areas in the study area. The wildlife in the area is also very rich (Anonymous, 2019a). According to the climatic parameters of the area, the average annual temperature is $13.2^{\circ} \mathrm{C}$, the average humidity is $77.5 \%$ and the rainfall is $87.7 \mathrm{~mm} /$ month (Anonymous, 2019b). 50\% of the area is forest and heathland, $30 \%$ is agricultural area, $9 \%$ is other areas (settlement, industry, etc.) and 1\% is meadows and pastures (Anonymous, 2019a).

Duzce province has 7 districts, 279 villages and 2 towns. The population of the area in 2018 is 387844 . Its population has increased by $65.4 \%$ from the day it became a province in 2000 (130632). The number of people per square kilometer in Duzce is 156 (Anonymous, 2019c-d). The economic structure the area is based on tourism, agriculture and industry. Due to the widespread forests, the study area is rich in the forestry industry and has also developed rapidly in other industrial areas as well thanks to industrial incentives to support development in the aftermath of 1999 earthquake. In 2017, in order to protect agricultural areas against urbanization and industry, Duzce Plain and its vicinity were declared agricultural protection sites. The most important issue to be mentioned about the agricultural activities in Duzce is the transformation of forest areas into hazelnut agricultural area for years (Anonymous, 2019a). Furthermore, the Büyük Melen Dam still under construction is planned to cover $75 \%$ of the water demand of Istanbul, which is $170 \mathrm{~km}$ away. The project was prepared in 1997 and construction started in 2001, the first phase was completed in 2007 and the work is still in progress (Anonymous, 2019e). The project is significant since it is the largest water supply project in Turkey. In this context, the study area is a very important drinking water basin.

The study area has an ecologically sensitive structure. The earthquake, landslide, erosion, flood and habitat fragmentation clearly reveal this fact. One of the most important examples is 17 August and 12 November 1999 earthquakes in 7.4 and 7.2 density according to the Richter scale. In these earthquakes, approximately 18 thousand 374 people were killed, and 48 thousand 901 people were injured (Anonymous, 2019d). There are also natural disaster risks such as mass movements, landslides, and floods along with earthquakes. Mass movement around the Duzce basin is widespread due to its abundant rainy climatic characteristics and geological and geomorphologic structure. In 1998, various mass movements occurred due to excessive precipitation. In this context, Duzce-Akçakoca Highway in Yazlık Dere, Melen River basin in the north of Cumayeri and Almacik Mount slopes are areas with landslide risks (Özaslan et al., 2001). In this context, it is stated that $12.8 \%$ of the area has high risk, $21.7 \%$ has high, 
$23.6 \%$ has medium, $16.8 \%$ has low, and $15.6 \%$ has very low landslide susceptibility. Furthermore, data on $9.5 \%$ of the area has not been produced (Anonymous, 2016). There is no significant difference between the north and south of Duzce in terms of landslide susceptibility. In the central part, landslide sensitivity is quite low. The main reason for this is the increase in height and slope as progressed north and south from the middle section. The landslide susceptibility is increased along the Çilimli Fault and the Duzce Fault in the East-West direction along the North Anatolian Fault. The landslide sensitivity is high on the slopes facing the north, northwest and northeast. A little more rainfall on the north-facing slopes makes the sensitivity higher. The landslide sensitivity is high on slopes with 10-30\% inclination. Vegetation is often forest depending on climate and recently transformed into hazelnut areas; thus, the natural balance of the slopes deteriorates and the landslide sensitivity increases (Kocabaş, et al., 2016). The rivers in the study area are mainly in the form of meanders and are quite twisted and the stream beds are very shallow. This situation constitutes the flood risk for Duzce basin (Özaslan et al., 2001). As a matter of fact, flood incidents that caused considerable loss of property occurred in 1995, 1997 and 1998, and similar cases are experienced every year (Tatar, 2005). Also, 21.4\% of the area has very severe, $18.2 \%$ has severe, $11.4 \%$ has medium; $19.5 \%$ has mild and $29.5 \%$ has very mild erosion risk (Anonymous, 2018). The human spread in the area (urbanization, industrialization, transportation, etc.) ignoring the habitats causes habitat fragmentation (Aydın et al., 2016), threatening both forest areas and biodiversity.

\section{Materials}

The main material of the study is composed of the maps, which are evaluated in order to reveal the natural and cultural characteristics of Duzce province, and which are used to create the sensitivity map. The other study materials consist of institutional reports on Duzce province and the scientific literature on landscape sensitivity. Maps used in the study are:

- 1/25000 scale digital Duzce Topographic Map produced by The Ministry of Defense, the General Directorate of Maps in 2000 (Anonymous, 2000) and updated road network map based on this map.

- 1/25000 scale digital Duzce Geological Map produced by Ministry of Energy and Natural Resources, General Directorate of Mineral Research and Exploration in 2002 (Anonymous, 2002).

- 1/25000 scale Digital Duzce Soil Map produced by the Ministry of Agriculture and Forestry, General Directorate of Agricultural Research and Policies in 2008-2010 (Anonymous, 2010).

- 1/25000 scale digital Duzce Forest Management Map produced by the Ministry of Agriculture and Forestry, General Directorate of Forestry in 2008 (Anonymous, 2008).

- 1/25000 scale digital Duzce Landslide Susceptibility Map produced by the Ministry of Internal Affairs Disaster and Emergency Management in 2016 (Anonymous, 2016).

- 1/125000 scale Duzce Erosion Risk Map produced by the Ministry of Agriculture and Forestry in 2018 (Anonymous, 2018).

- In the study, ArcGIS 9.3 software was utilized to create some thematic maps and sensitivity maps. 


\section{The theoretical basis of methods}

As Brunsden states, landscape sensitivity should be sought in landscapes resistance against and their responses to the forces of change (Thomas, 2001). Barabas et al. (2014) defined the sensitivity analysis as the examination of how ecological variables of interest respond to changes in external conditions. Usher (2001) emphasized that starting to think primarily about the landscape; the main natural systems that determine the structure of the landscape; and then about actions that change the natural systems are the best ways to determine sensitivity. In addition, it was also emphasized that changes and their magnitudes have both spatial and temporal components and that these components are an integral part of the sensitivity (Usher, 2001). In this context, to determine the sensitivity of landscape, some researchers are interested in related landscape components (inclination, aspect, proximity to water resources, etc.); some researchers consider ecological processes (erosion, landslide, desertation, climate change, habitat fragmentation, etc.); some others consider both as a combination parameter (Gordon and Sutherland, 1993; Thomas, 2001; Penghua et al., 2007; Mingwu, 2010; Wang and Bian, 2011; Aretano et al., 2015; Kesoretskikh et al., 2015; Bede-Fazekas et al., 2017; Haara et al., 2017; Hussain et al., 2018; Shi et al., 2018; Chia et al., 2019). The reason for the holistic evaluation of the parameters is that "anyone or more landscape components/ecological processes may be sensitive to change in certain situations and that the change in a component may trigger instability in any part of the system." For, the landscape is an intrinsically complex system, and the sub-systems can exhibit concurrent but opposite behaviours (Phillips, 1999; Usher, 2001; Thomas, 2001).

In the study, it was decided to conduct a sensitivity analysis based on the landscape processes including the components of the landscape. Landscape processes indicate a process depending on landscape components. Therefore, the analysis of processes will also allow the components to be analyzed at the same time. In addition, the spatial heterogeneity will be ensured, and excessive data will be avoided, and landscape systems will be evaluated with a reductionist approach.

Erosion risk, landslide susceptibility, water infiltration and habitat fragmentation processes were evaluated as parameters within the scope of the study. The efficiency of these processes and the existence of reliable spatial data related to these processes or the possibility of being produced were effective in the selection of the parameters and the landscape of the study area

The erosion sensitivity evaluated in the study is a parameter that has been evaluated since the first studies on landscape sensitivity (Thomas, 2001; Penghua et al., 2007; Mingwu, 2010; Wang and Bian, 2011). Erosion refers to the movement of upper soil due to various factors. Erosion is also important in terms of exploring the relationship between landscape pattern and ecological process. Landscape pattern, type of vegetation, soil properties, precipitation, etc. are some of the factors for erosion (Fu and Bruce Jones, 2013). In addition, as Thomas (2001) states, the soil has the clearest expression of landscape complexity, and it is sensitive to many landscape components such as rocks, precipitation, slope, aspect etc.

The landslide is another parameter that affects the landscape and is important for landscape sensitivity (Thomas, 2001). The landslide is a sudden mass movement of soil and substrate in the sloping areas. Landslides can cause many changes in landscape hydrology, vegetation cover, habitat, sediment load, biodiversity, organism movement, etc. Landslides, especially in mountainous landscapes, are one of the common problems 
along with precipitation and steep slope and should be accordingly evaluated in sensitivity process (Walker and Shiels, 2013).

Water is an important component of life and hence, landscape. In this context, the hydrologic cycle is one of the important processes in the landscape. The water is in continuous motion inside atmosphere, hydrosphere and lithosphere layers. Precipitation water's passing through vegetation cover, soil and rock layers to reach the impermeable layers thanks to gravity and slope effects is called the water process in the landscape or landscape's water function (Karadağ, 2019). This infiltration of water is important for landscape sensitivity and is considered as a parameter (Aydin et al., 2018).

Habitat fragmentation is one of the other important sensitivity criteria in the landscape (Thomas, 2001; Penghua et al., 2007; Mingwu, 2010; Wang and Bian, 2011; Aretano et al., 2015; Bede-Fazekas et al., 2017; Chiet et al., 2019). For, habitat loss and/or fragmentation have been identified as perhaps the most important driving force of the global biodiversity crisis. Landscape connectivity is critical to the viability of many types of species (Forman and Godron, 1986; Cushman et al., 2010). Habitat fragmentation decreases disintegration, increases mortality and decreases genetic diversity (Cushman et al., 2010; Kosydar, 2014). In addition, the vegetation cover destroyed by habitat fragmentation ceases its duty to protect soil and water resources, (Babalık et al., 2019) and changes the landscape pattern. Landscape pattern is a concrete reflection of the spatial heterogeneity of the landscape (Penghua et al., 2007). It is also the result of ecological processes affecting different spatial and temporal scales (Bolliger, 2005).

Earthquake risk zones are not taken into consideration in the study. For, the whole area is within the 1st-degree earthquake zone.

\section{Methods (data acquisition and analyses)}

The study consists of three stages. These are; determination of parameters to be evaluated in sensitivity analysis; obtaining the parameter data and making the necessary analysis in this process; holistic analysis of selected parameters on the basis of sensitivity analysis (Fig. 2).

Düzce Erosion Risk map was obtained from the relevant unit of the Ministry of Agriculture and Forestry. The map was created by Revised Universal Soil Loss Equation (RUSLE) method. The average soil loss per year hectare with RUSLE method is generally determined by the holistic evaluation of six different parameters. These parameters are; rainfall-runoff erosivity, soil erosion erodibility, slope length, slope steepness and support practice. Erosion risk status in the map is classified as very severe, severe moderate, mild and very mild (Erpul et al., 2018). Also, erosion risk map has been considered as an erosion sensitivity map within the scope of this study. Because risk maps are produced in order to reveal the loss of life and property to be affected by the change in landscape. Therefore, in this study, erosion risk maps were used to determine areas sensitive to erosion. This classification was evaluated using a scale between 1 and 5 according to expert opinions. According to the evaluation, the areas with very severe erosion risk had 5 points (too high sensitivity) followed by severe with 4 points (high sensitivity); moderate with 3 points (medium sensitivity); mild with 2 points (low sensitivity) and very mild with 1 point (too low sensitivity). Later, these scores were added to the database of erosion risk maps with ArcGIS 9.3 software and an erosion sensitivity map was created. 


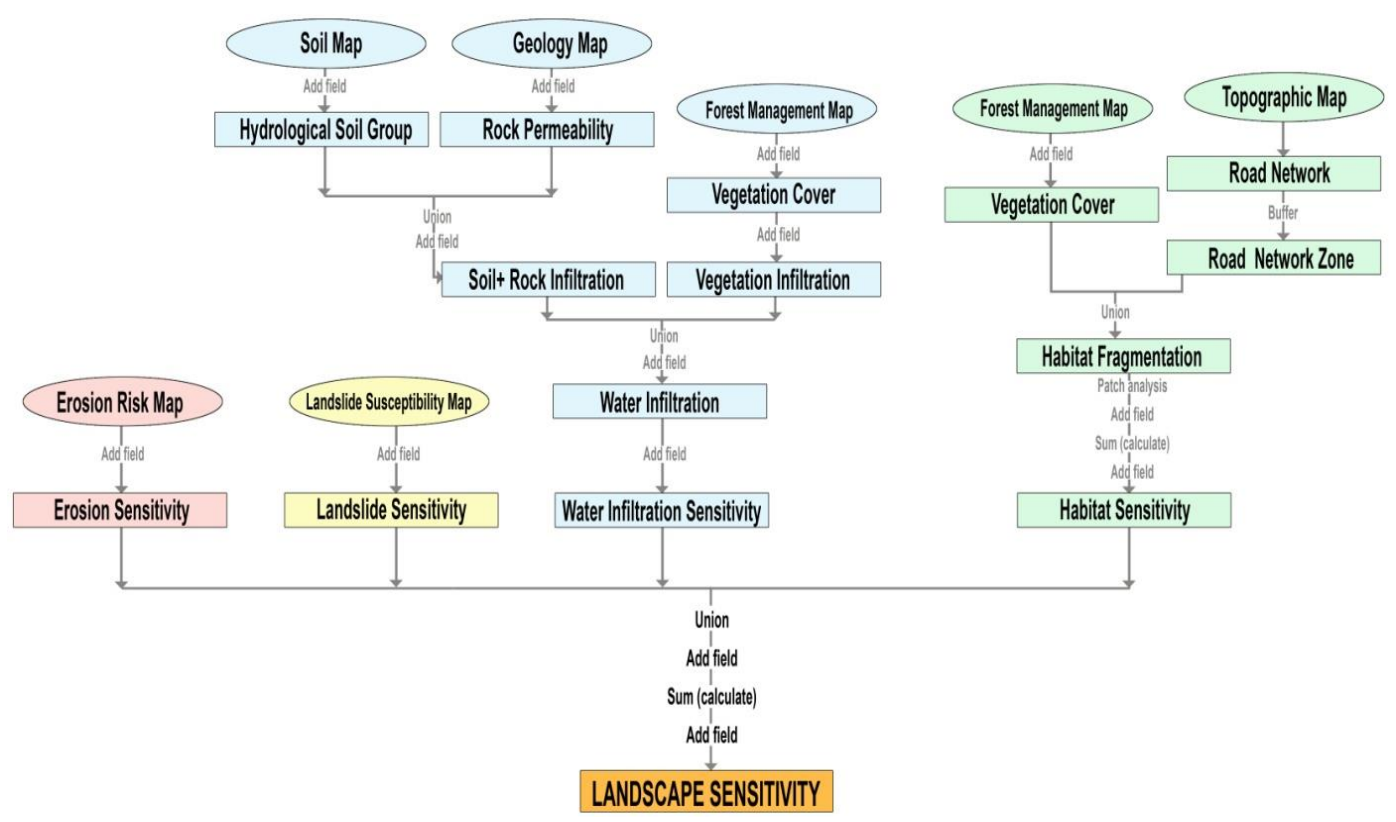

Figure 2. Landscape sensitivity analysis model (parameters, data, and analysis process)

Düzce Landslide Susceptibility Map was obtained from the relevant unit of the Ministry of Internal Affairs. The map was generated by the Frequency Ratio method. In this method, after the determination of the parameters which come out as a result of the field observations, the parameter maps and the landslide polygons are coupled. It provides the proportional landslide possibility in other areas based on the characteristics of the corresponding parameters. In determining landslide sensitivity, lithology, height, curvilinearity, aspect and slope were considered holistically. Landslide susceptibility status is classified as very high, high, medium, low, very low on the map (Kocabaş et al., 2016). This classification was evaluated by using a scale between 1 and 5 according to 3 expert opinions. According to the evaluation, the areas with very high landslide susceptibility have 5 points (very high sensitivity); high areas have 4 points (high sensitivity); medium areas have 3 points (medium sensitivity), low areas have 2 points (low sensitivity) and very low areas have 1 point (very low sensitivity). These points were then added to the database of the landslide susceptibility map with the ArcGIS 9.3 software and a landslide sensitivity map was created.

Water infiltration map was created within the scope of the study. Water process analysis method was used to create the water infiltration map of the study area. Within the scope of the method, 1/25000 scaled digital soil map, geology map and forest management map were used (Anonymous, 2002; Anonymous, 2008; Anonymous, 2010). Hydrological soil groups from the soil map; the rock permeability from the geology map, vegetation cover from the forest management map, and then vegetation infiltration data were produced. These data are then were analyzed according to the water process analysis method used by Uzun et al. (2015) and Karadağ (2019), and water infiltration data were generated (Table 1). Then, hydrological soil groups and rock permeability data were evaluated by union analysis and soil + rock infiltration data were obtained in the first stage. In the second stage, this data was subjected to union analysis with vegetation infiltration, and water infiltration data consisting of five classes were formed. This map was then evaluated by using a scale between 1 and 5 according 
to 3 expert opinions. According to the evaluation, areas with very high water infiltration have 5 points (very high sensitivity); high areas have 4 points (high sensitivity); medium areas have 3 points (medium sensitivity); low areas have 2 points (low sensitivity) and very low areas have 1 point (too low sensitivity). These points were later added to water infiltration map database with ArcGIS 9.3 software and a water infiltration sensitivity map was created.

A habitat fragmentation map was created within the scope of the study. The data obtained by using the patch-corridor-matrix model in the creation of the habitat fragmentation map of the study area were analyzed and interpreted by the Patch Analysis 4 software, an interface of ArcGI9.3 developed by Rempel (2010). In this context, Düzce Forest Management Map was used, and vegetation cover data were prepared from this map. In this data, the forest cover was examined and four spots (coniferous forest, leafy forest, mixed forest and pasture) were defined. The data were subjected to union analysis with the road map in order to reveal the fragmentation. The road map was prepared from 1/25000 scaled digital topographic map. However, before the analysis, $4 \mathrm{~m}$ effect zones were formed on the roads by way of proximity (buffer) analysis in order to involve the effects of the roads on the environment. The data obtained from the Union analysis were accepted as the base data of the habitat fragmentation. These data were then analyzed at class level with the Patch Analysis module, which was developed by Rempel (2010) as an interface to ArcGIS 9.3. The analysis was carried out in two stages. In the first stage, patch size and number, patch shape and edge properties of patches were determined by spatial statistics based on patch analysis. As a result of the analysis, No of Patches (NumP) Related to patch size and number, Class Area (CA) and Mean Patch Size (MPS), Mean Shape Index (MSI) related to patch shape, Mean Perimeter-area Ratio (MPR), Mean Patch Fractal (MPFD) values, and Edge Density (ED) values were obtained. In the second stage, core areas related to patches were determined on the basis of patch analysis. During the analysis, a $100 \mathrm{~m}$ edge zone was identified in order to assess fragmented forest edges and their effects on the living creatures in the inner habitats. Then, total core area (TCA), total core area index (TCAI) and Core Area Density (CAD) values were obtained by spatial statistics on the basis of patch analysis. All obtained spatial values were evaluated on the basis of the studies by Forman and Godron (1986), Rempel (2010) and Uzun (2012). In this context, the result was that "NumP increased, MPS and CA decreased, fragmentation decreased; MPAR and MSI values decreased, MPFD value closed to 1 and fragmentation decreased; ED increased, fragmentation increased; TCAI and CAD increased, fragmentation decreased." Decreased of that fragmentation was evaluated as an increase in sensitivity. For, in larger patches, biodiversity and forest cover is high and these areas should be considered a priority in conservation. In order to map this condition, first, the sensitivity status of each patch was scored between 1 and 5 . Then, the scores obtained from these four parameters were totalized, and the habitat total sensitivity score was determined and reclassified. In this context, the total score for each patch from four parameters is maximum 20 and minimum 4. These scores are divided into five classes (very high, high, medium, low, very low) according to the sensitivity status. The range of points used in the formation of the classes was found to be about 3 , calculated by "subtracting the lowest score from the highest, and dividing the sum into six." According to this assessment, areas with very high sensitivity have 20-19 points; high sensitivity have 19-16 points; moderate sensitivity have 15-12 points; low sensitivity have 11-8, and too low sensitivity has 4-7 points. Finally, by calculating the 
total scores obtained from four parameters of each patch, sensitivity scores according to the class range were determined. Then, the total habitat sensitivity score was calculated with ArcGIS 9.3, which was processed in a new field in the patch map database and a habitat vulnerability map was created. Uzun's (2012) study was used in the analysis and evaluation process.

The final analysis within the scope of the study is the union analysis performed to ensure a holistic assessment of all data, after the creation of the four data sensitivity parameters to be evaluated in the sensitivity analysis. Four data are subjected to union analysis. A new field is added to the database of the resulting map. Later, calculation of landscape sensitivity total score of each polygon is done with the following formula:

Landscape sensitivity total score $=$ Erosion sensitivity score + Landslide sensitivity score

+ Water infiltration sensitivity score + Habitat sensitivity score

The total score of each polygon was written to the new field. Then the maximum and minimum scores are determined, and the difference is divided into six so that the sensitivity can be defined by a scale of 5 (sensitivity is very high, sensitivity is high, sensitivity is medium, sensitivity is low, sensitivity is very low). The score interval of these 5 classes is defined with the number obtained. Finally, the total sensitivity score received by each polygon is determined based on specific sensitivity state, and this detection is processed in the new data added to the database of the data obtained from the union analysis and a total sensitivity map is generated.

\section{Results}

In this study, firstly, data sensitivity parameter maps in Figure 3 are produced. When the database of the maps was examined, the data given in Table 1 was obtained.

When the erosion sensitivity map was examined, it was seen that the erosion sensitivity increases in the mountainous areas to the north of the area. In the southern and inner parts of the area, erosion sensitivity decreases (Fig. 3). When the erosion sensitivity map database was evaluated, it was seen that the sensitivity in $21.4 \%$ of the area was very high while it was high in $18.2 \%$, medium in $11.4 \%$, low in $19.5 \%$ and very low in $29.5 \%$ (Table 1).

Table 1. Sensitivity (sen.) parameter areas in the study area, (\%)

\begin{tabular}{|c|c|c|c|c|}
\hline \multirow{2}{*}{$\begin{array}{c}\text { Sensitivity } \\
\text { degree }\end{array}$} & \multicolumn{4}{|c|}{ Sensitivity parameters } \\
\hline & $\begin{array}{c}\text { Erosion sen. area } \\
(\%)\end{array}$ & $\begin{array}{c}\text { Landslide sen. } \\
\text { area }(\%)\end{array}$ & $\begin{array}{c}\text { Water infiltration sen. } \\
\text { area }(\%)\end{array}$ & $\begin{array}{c}\text { Habitat sen. area } \\
(\%)\end{array}$ \\
\hline Very high & 21.4 & 12.8 & 0.4 & - \\
\hline High & 18.2 & 21.7 & 11.6 & 33.1 \\
\hline Medium & 11.4 & 23.6 & 80.6 & 3.4 \\
\hline Low & 19.5 & 16.8 & 4.2 & 16.8 \\
\hline Very low & 29.5 & 15.6 & 3.2 & - \\
\hline
\end{tabular}

When the landslide sensitivity map was examined, it was seen that the landslide sensitivity increases in the mountainous areas to the north of the area. This is due to the high slope, elevation, fault lines and habitat fragmentation in these areas. In the inner 
parts of the area, landslide sensitivity is low (Fig. 3). When the landslide sensitivity map database was evaluated, it was seen that the sensitivity in $12.8 \%$ of the area was very high while it was high in $21.7 \%$, medium in $23.6 \%$, low in $16.8 \%$ and very low in $15.6 \%$ (Table 1). Data for $9.5 \%$ of the area was not produced

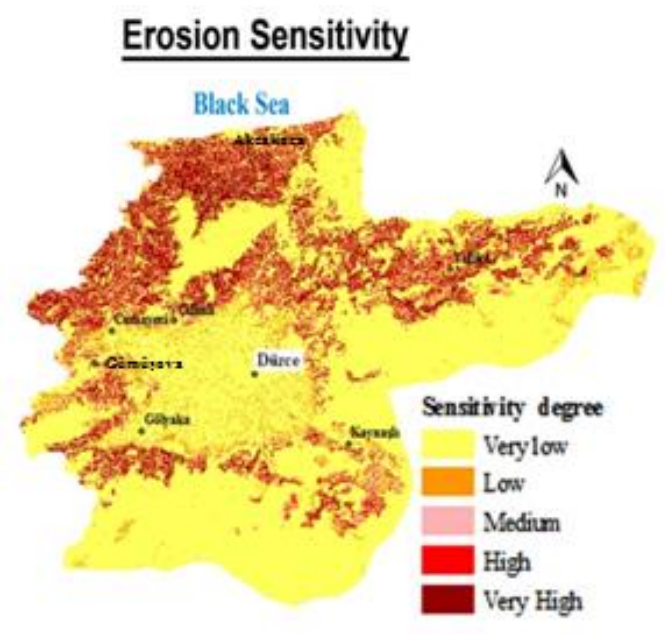

Water Infiltration Sensitivity

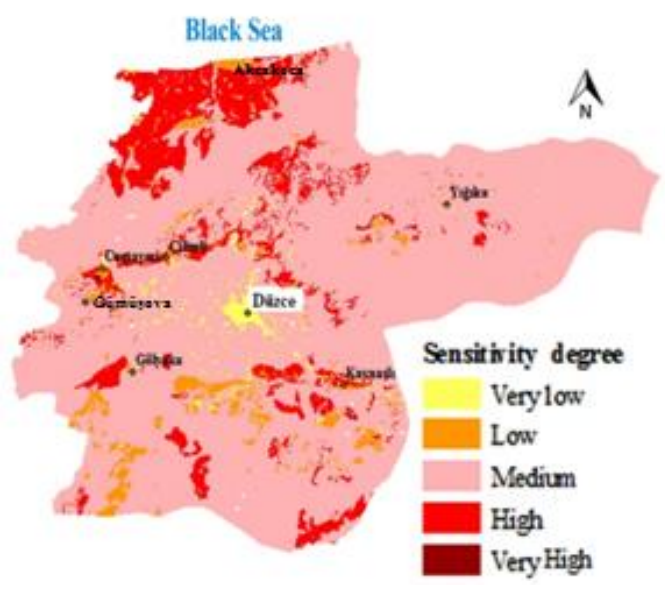

\section{Landslide Sensitivity}

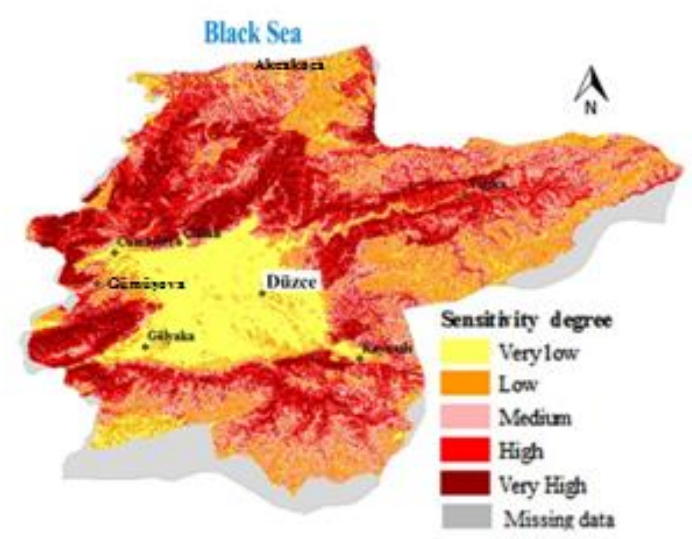

Habitat Sensitivity

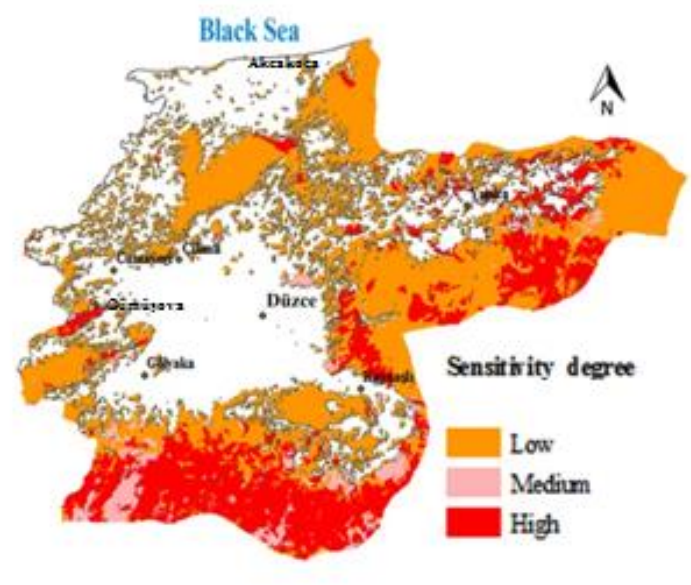

Figure 3. Maps of landscape sensitivity parameters

When the water infiltration sensitivity map was examined, it was seen that the water infiltration sensitivity in the area is generally moderate (except for residential areas/artificial surfaces). Only the Black Sea coast and from the coast to the inland increase sensitivity (Fig. 3). When the water infiltration sensitivity map database is evaluated, it was seen that the sensitivity in $0.1 \%$ of the area was very high while it was high in $11.6 \%$, moderate in $80.6 \%$, low in $4.5 \%$ and very low in $3.2 \%$ (Table 1 ).

The habitat sensitivity map of the area was produced based on vegetation cover. The habitat patches in the area were evaluated as "coniferous forest, leafy forest, mixed forest, pastures" and the breaks in these spots were analyzed based on conservation priority. In order to reveal the fragmentation in the patches, the destructive power of the roads was evaluated and a total of 3158 patches were detected in the area by union analysis. Patch size and number, patch shape, patch edge and core area parameters 
related sub-criteria values were determined. These values were scored based on the studies by Forman and Godron (1986), Rempel (2010) and Long (2012) and expert opinions as the increase of fragmentation is accepted as a sensitivity-lowering effect; and mixed forests received 16 points, pastures 14 points, coniferous forests 12 points and leafy forests 10 points. When these scores were evaluated according to the sensitivity classification in the area, it was determined that mixed forests had high sensitivity while coniferous forests and pastures had moderate, and leafy forests had low sensitivity. When the habitat sensitivity map was examined, it was seen that the sensitivity decreased in the eastern and southern parts of the area. This situation shows that habitat fragmentation occurs in this area (Fig. 3). When the habitat sensitivity map database was evaluated, it was seen that the sensitivity in $33.1 \%$ of the area was high while it was low in $16.8 \%$ and moderate in $3.4 \%$ (Table 1). $46.7 \%$ of the area has not been evaluated as patch.

As a result of overlay analysis of four sensitivity parameter data related to the study area, Duzce Province landscape Sensitivity Map in Figure 4 was obtained. When the sensitivity map database was examined, it showed that the maximum landscape sensitivity total score in the field was 18 and the min total score was 4 . When scores are ranked according to their sensitivity, 16-18 points were considered very high sensitivity, 13-15 points were considered high, 10-12 points was considered moderate, 7-9 points was considered low and 4-6 points was considered very low. When the landscape sensitivity map database was evaluated, it was seen that the sensitivity in $38.6 \%$ of the area is low while it is medium with $30.6 \%$, very low with $21.7 \%$, high with $8.2 \%$ and very high with $8.2 \%$. These findings indicate that $39.7 \%$ of the area is sensitive (medium, high and very high) (Fig. 4).

When the landscape sensitivity map is examined, it is seen that very low sensitivity areas are located in Duzce plain. In these areas, especially water infiltration has affected sensitivity. There are intense land uses like settlements, agriculture, and industry in these areas. Low sensitivity areas are located in the south and southeast of the area. In these areas, habitat fragmentation and water infiltration have affected sensitivity and the settlement is not dense. Medium sensitivity areas are spread throughout the study area. Erosion, landslide and water infiltration are effective in sensitivity in these areas. There are especially rural settlements and forests in these areas. High sensitivity areas are concentrated, especially located in the northwest of the area. In these areas, erosion, landslide and water infiltration sensitivity is high. Very high precision areas are located in the north of the area. These areas take up very little space in the area. Erosion, landslides, water infiltration and habitat sensitivity are high in these areas (Fig. 4).

\section{Discussion}

The deterioration of the ecological balance has been a common problem in the world since the industrial revolution. Many researchers in different disciplines have done various researches on this concept (Shi and Tong, 2019). Landscape sensitivity analysis is one of these studies.

Landscape studies has a significant public interest in cultural, ecological, environmental and social areas and is a resource that is conducive to economic activity and that can contribute to job creation, conservation, management and planning. In this context, it is one of the key elements of individual and social welfare (Anonymous, 2017). Therefore, understanding and recognizing the landscape is very important. In the 
process of recognizing and understanding the landscape, sensitive landscapes are very important. This is because sensitive landscapes are the most intensively associated with ecological-environmental changes and tend to be most prone to ecological problems (Forman, 1995; Hong et al., 2017). In this context, it is aimed to reveal areas which are sensitive to natural/anthropogenic factors, have a high potential for change under external factors and have priority in spatial development (Thomas, 2001; Shi et al., 2018; Chia et al., 2019). In this study, mapping of landscape sensitivity areas is the main objective. In this study, an ecology based sensitivity map has been created for spatial planning. This map is practical data for many occupational disciplines. Uzun et al. (2015), Demiroğlu (2016), Cengiz et al. (2017) and Karadağ (2019) emphasize that such practical data is necessary for ecology-based planning.

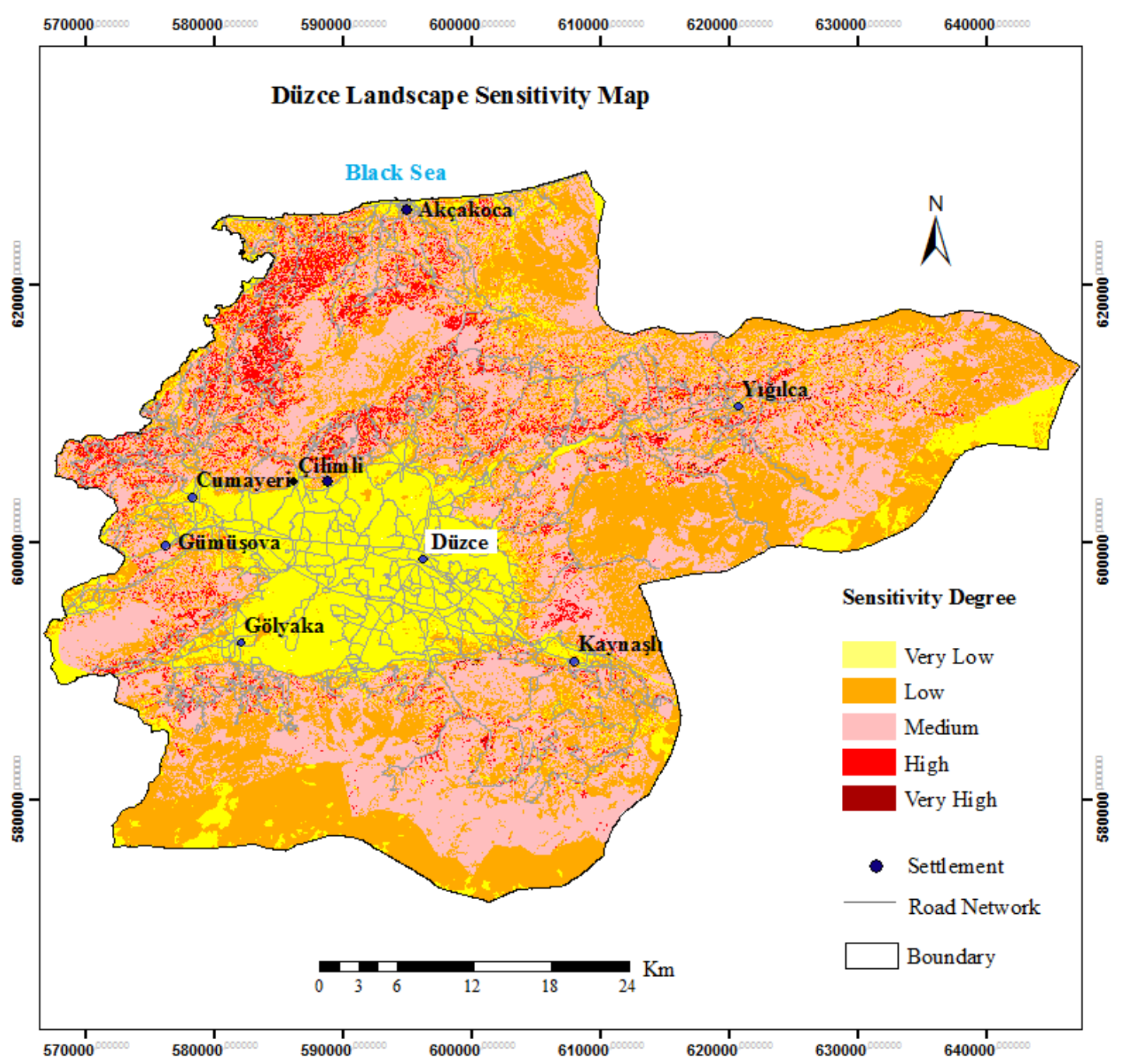

Figure 4. Duzce landscape sensitivity map

In this study, landscape sensitivity map is presented as a result of sensitivity analysis. In the sensitivity analysis, like many researchers (e.g., Thomas, 2001; Penghua et al., 2007; Mingwu, 2010; Wang and Bian, 2011; Fu and Bruce Jones, 2013; Walker and Shiels, 2013; Aretano et al., 2015; Bede-Fazekas et al., 2017; Aydın et al., 2018; Chia et 
et al., 2019) ecological processes were evaluated holistically. Ecological processes to be included in the analysis are shaped according to the purpose of the study. In this study, four different ecological processes (erosion sensitivity, water infiltration sensitivity, habitat fragmentation sensitivity) were considered as parameters. The processes were selected on the basis of the basic processes that have an impact on the landscape character of the study area. In addition, these parameters and natural and cultural landscape components could be evaluated together.

Sensitivity parameter maps and landscape sensitivity map obtained in the study showed that the sensitivity structure of the study area has a complex structure. Mapping of this complex structure is very important in terms of spatial planing and land use. Aydin et al. (2018) have reached similar results and map regarding the landscape sensitivity of the study area. They also emphasized the importance of landscape sensitivity map for spatial planning.

The study area has significant ecological sensitivities. However, the land uses in the study area were not developed with ecology-based plan decisions. The creation of the sensitivity map is necessary in order to determine the sensitive areas/ecosystems in the area and to determine the protection priority compared to others. For, areas with high landscape sensitivity are areas that need to be protected. The exposure to human uses and their severity may cause vulnerability issues and may pose risk situations. In this context, sensitivity maps can be considered as a basis for suitable analysis used in the development of land-use decisions. For, space use should be considered on the basis of sensitivity due to its effects on the loss of ecosystems as stated by Saran et al. (2019).

In this study, the reduction of the data to be analyzed with the evaluation of ecological processes and a reductionist approach was exhibited. However, many researchers like Gordon and Sutherland (1993), Penghua et al. (2007), Wang Mingwu (2011), and Bian (2011), Aretano (2015), Haara et al. (2017) Hussain et al. (2018), Shi et al. (2018), Chia et al. (2019) evaluated ecological process and landscape components together. As Thomas (2001) points out, landscape sensitivity is more easily analyzed with reductionist approaches. In addition, the performance of the ArcGIS program was not forced by the reduction of data.

\section{Conclusion}

In this study, a model for the development of landscape sensitivity areas is presented and the reasons for this approach are explained. The most important result of the study is to produce a map describing the landscape sensitivity of the study area. The landscape sensitivity map of the study area is a data that is compatible with ecological principles, produced by scientific methods, compatible with technological tools and can be integrated with similar analyzes. It is an ecological guide for various spatial plans (landscape planning, construction planning, open and green space planning, green infrastructure planning, etc.). It may contribute to the development of policies for ecology-based protection, usage, planning, management, etc. They can be legally defended due to their scientific and transparent nature during production/preparation. In addition, sensitivity maps are base data that provide the exposure of field uses, vulnerability and risk analysis.

In the study, only four parameters were evaluated in determining landscape sensitivity. However, a wide range of parameters (habitat sensitivity, earthquake sensitivity, etc.) can be included in the analysis to further enhance landscape sensitivity. 
Increasing parameters will change the total landscape sensitivity in the area. Thus, a more accurate result will be achieved. The landscape sensitivity map in spatial planning processes is an impressive guide. However, it should be noted that each parameter map should be included in the decision-making process and evaluated.

Determination of parameters is very important in sensitivity analysis. The selection of sensitivity parameters should take into account the ecological processes that direct the formation of the area or ecological sensitivities in the area.

The spatial data used in the study are digital maps with a scale of $1 / 25000$. These data are of a higher scale and might be more directives for planning decisions. For decisions on a local scale, sensitivity maps developed using smaller-scale maps should be used. For this reason, further sub-scale data should be used to make decisions on local scale (cities, rural settlements, etc.).

In the assessment of the sensitivity of the maps used in the production of the sensitivity map, a scale of sensitivity (1-5) was created and scoring was made by applying 3 expert opinions. In order to increase objectivity, the number of experts can be increased, and the scores can be analyzed by statistical methods (e.g. analytic hierarchy process, Delphi technique) and transferred to the mapping process. Thus, objectivity is further increased.

Intensive land use in the study area has developed in very low sensitivity area. These areas are not sensitive in terms of erosion and landslides. There is also no vegetation cover. However, they are sensitive areas for water infiltration. But these plans were not developed on the basis of landscape sensitivity and the necessary measures were not taken. Because there is no such legal justification in the spatial planning processes of the study area. Therefore spatial planning related to the study area should be developed on the basis of landscape sensitivity maps. For example, in areas with high sensitivity, necessary protection decisions should be made and appropriate planning made. The rationale for these decisions should be clearly demonstrated on the basis of scientific and technological data.

As a result, landscape sensitivity map is one of the important keys in order to develop ecologically-based decisions related to space. Therefore, its usage as a basis map for spatial planning is a need beyond desire. In addition, the preparation and use of these maps as a base should be made legally mandatory.

\section{REFERENCES}

[1] Adger, W. N. (2006): Vulnerability. - Global Environmental Change 16(3): 268-281.

[2] Anonymous (2000): 1/25000 Scale Digital Düzce Topographic Map. - Republic of Turkey Ministry of National Defense, General Directorate of Mapping, Ankara, Turkey (in Turkish).

[3] Anonymous (2002): 1/25000 Scale Digital Düzce Geological Map and Report. Republic of Turkey Ministry of Energy and Natural Resources, General Directorate of Mineral Research and Exploration, Ankara, Turkey (in Turkish).

[4] Anonymous (2008): 1/25000 Scale Digital Düzce Soil Map and Report. - Republic of Turkey Ministry of Agriculture and Forestry, General Directorate of Agricultural Research and Policies, Ankara, Turkey (in Turkish).

[5] Anonymous (2010): 1/25000 Scale Digital Düzce Forest Cover Map and Report. Republic of Turkey Ministry of Agriculture and Forestry, General Directorate of Forestry. Ankara, Turkey. 
[6] Anonymous (2016): 1/25000 Scale Digital Düzce Landslide Susceptibility Map. Republic of Turkey Ministry of Interior, Disaster and Emergency Management Presidency, Ankara, Turkey (in Turkish).

[7] Anonymous (2017): Presentation of the European Landscape Convention of the Council of $\quad$ Europe. - $\quad$ www. rm.coe.int/CoERMPublicCommonSearchServices/DisplayDCTMContent?documentId=0 9000016802f7dfd (date of access: 19.02.2019).

[8] Anonymous (2018): 1/25000 Scale Digital Düzce Erosion risk Map. - Republic of Turkey Ministry of Agriculture and Forestry, General Directorate of Combating Desertification and Erosion Ankara, Turkey (in Turkish).

[9] Anonymous (2019a): Duzce Province Environmental Situation Report in 2017. - Duzce Provincial Directorate of Environment and Urbanization. www.webdosya.csb.gov.tr (date of access: 23.01.2019) (in Turkish).

[10] Anonymous (2019b): Duzce Province Clean Air Action Plan in 2015. - Duzce Provincial Directorate of Environment and Urbanization. www.webdosya.csb.gov.tr (date of access: 23.01.2019) (in Turkish).

[11] Anonymous (2019c): Duzce Address Based Population Registration System 2018. Duzce Provincial Directorate of Population and Citizenship. www.duzcenufus.gov.tr (date of access: 23.01.2019) (in Turkish).

[12] Anonymous (2019d): Duzce Geological Structure. - Düzce Governorship. http://www.duzce.gov.tr/jeolojik-yapi (date of access: 11.04.2019) (in Turkish).

[13] Anonymous (2019e): Melen Dam. - Duzce Municipality. http://www.duzce.bel.tr/detay.asp?id=29919 (date of access: 11.04.2019) (in Turkish).

[14] Aretano, R., Semeraro, T., Petrosillo, I., De Marco, A., Pasimeni, M. R., Zurlini, G. (2015): Mapping ecological vulnerability to fire for effective conservation management of natural protected areas. - Ecological Modelling 295: 163-175.

[15] Aydın, B., Tezer, A., Turkay, Z., Yılmaz Kaya, M., Kutay Karacor, E., Guler, İ., Uzun, O, Okay, N., Terzi, F., Köylü, P., Satilmis, E., Kara, D. (2018): Resilience through participatory planning for the integrated ecological risks in Duzce. - Resilience Journal 2(2): 105-121.

[16] Babalık, A. A., Yazıc1, N., Fakır, H., Dursun, I. (2019): Determination of the certain vegetation characteristics of Kizilova forest pasture located in the south of Turkey. Applied Ecology and Environmental Research 17(1): 521-532.

[17] Barabas, G., Pasztor, L., Meszena, G., Ostling, A. (2014): Sensitivity analysis of coexistence in ecological communities: theory and application. - Ecology Letters 17: 1479-1494.

[18] Bede-Fazekas, A., Czúcz, B., Somodi, I. (2017): Vulnerability of natural landscapes to climate change - a case study of Hungary. - Quarterly Journal of the Hungarian Meteorological Service 121(4): 393-414.

[19] Birkmann, J., Wisner, B. (2006): Measuring the un-measurable the challenge of vulnerability. - www. d-nb.info/1029694141/34 (date of access: 19.02.2019).

[20] Bolliger, J. (2005): Simulating complex landscapes with a generic model: sensitivity to qualitative and quantitative classifications. - Ecological Complexity 2: 131-149.

[21] Boström, C., Pittman, S. J., Simenstad, C., Kneib, R. T. (2011): Seascape ecology of coastal biogenic habitats: advances, gaps, and challenge. - Marine Ecology Progress Series 427: 191-217.

[22] Campbell, C., Conger, S., Gould, B., Haegeli, P., Jamieson, B., Statham, G. (2016): Technical aspects of snow avalanche risk management. - Canadian Avalanche Association, Revelstoke, BC, Canada.

[23] Chia, Y., Zhang, Z., Gao, J., Xie, Z., Zhao, M., Wanga, E. (2019): Evaluating landscape ecological sensitivity of an estuarine island based on landscape pattern across temporal and spatial scales. - Ecological Indicators 101: 221-237. 
[24] Cegiz, A. E., Karadağ, A. A., Demiroğlu, D. (2017): Importance of landscape planning for sustainable spaces. - International Congress of the New Approaches and Technologies for Sustainable Development, Isparta, Turkey, Congress Book 1(1): 4-16.

[25] Cushman, S. A., Landguth, E., L., Flather, C., H. (2010): Climate change and connectivity: assessing landscape and species vulnerability. - Phase 1-Final Report. www.fws.gov/southwest/es/documents/R2ES/LitCited/LPC_2012/Cushman_et_al_2010. pdf (date of access: 19.02.2019).

[26] Damiano, H. R., Umberger, M., Monitz, G., Friedman, J., Hariri, M., Tehranifar, R., Grassi, C., Lindsey, E. (2014): NYC's Risk Landscape: A Guide to Hazard Mitigation. The NYC Department of City Planning \& The NYC Mayor's Office of Recovery and Resiliency. www1.nyc.gov/assets/em/downloads/pdf/hazard_mitigation/nycs_risk_landscape_a_guid e_to_hazard_mitigation_final.pdf (date of access: 26.03.2019).

[27] Demir, S. (2019): Landscape dynamics changes of the protected Mary Valley, Turkey. Applied Ecology and Environmental Research 17(2): 3591-3613.

[28] Demiroğlu, D., Pekin Timur, U. Karadağ, A. A., Cegiz, A. E. (2014): Ecology Based Contemporary Urbanism Approaches. - In: Efe, R., Onay, T. T., Sharuho, I., Atasoy, E. (eds.) Urban and Urbanization. St. Kliment Ohridski Universty Press, Bulgaria.

[29] Dunning, J. B., Danielson, B. J., Pulliam, H. R. (1992): Eco-logical processes that affect populations in complex landscapes. - Oikos 65: 169-175.

[30] Erpul, G., Şahin, S., Küçümen, A., Akdağ, M. A., Demirtaş, İ., Çetin, E., İnce, K. (2018): Erosion Model and Dynamic Monitoring System (DEMIS) Turkey Water Erosion Statistics. - Technical Report. Republic of Turkey Ministry of Agriculture and Forestry General Directorate of Combating Desertification and Erosion, Turkey (in Turkish).

[31] Farina, A. (2001): Landscapes and their ecological components. www3.udg.edu/cgpt/Almo\%20Farina/Biosphere.PDF (date of access: 19.02.2019).

[32] Farina, A. (2008): The landscape as a semiotic interface between organisms and resources. - Biosemiotics 1(1): 75-83.

[33] Farina, A., Pieretti, N. (2012): The soundscape ecology: a new frontier of landscape research and its application to islands and coastal system. - Journal of Marine and Island Cultures 1(1): 21-26.

[34] Forman, R. T. (1995): Some general principles of landscape and regional ecology. Landscape Ecology 10(3): 133-142.

[35] Forman, R. T., Godron, M. (1986): Landscape Ecology. - John Wiley \& Sons, New York.

[36] Fu, B., Bruce Jones, K. (2013): Landscape Ecology for Sustainable Environment and Culture. - Springer Science, London.

[37] Godrdon, J. E., Sutherland, D. G. (1993): Quaternary of Scotland. - Geological Conservation Review Series (No: 6). Chapman and Hall, London.

[38] Golobič, M., Žaucer, L. B. (2010): Landscape planning and vulnerability assessment in the Mediterranean. - Regional Activity Centre for the Priority Actions Programme, Croatia. www.pap-thecoastcentre.org/pdfs/Landscape\%20Vulnerability.pdf (date of access: 19.02.2019).

[39] Haara, A., Store, R., Leskinen, P. (2017): Analyzing uncertainties and estimating priorities of landscape sensitivity based on expert opinions. - Landscape and Urban Planning 163: 56-66.

[40] Hong, W., Guo, R., Su, M., Tang, H., Chen, L., Hu, W. (2017): Sensitivity evaluation and land-use control of urban ecological corridors: a case study of Shenzhen, China. - Land Use Policy 62: 316-325.

[41] Hussain, A., Singh, G., Rawat, G., S. (2018): Landscape Vulnerability Assessment Using Remote Sensing and GIS Tools in the Indian Part of Kailash Sacred Landscape. - The International Archives of the Photogrammetry, Remote Sensing and Spatial Information Sciences, Volume XLII-5, 20-23 November 2018, Dehradun, India. 
[42] İlboğa, M., Aygül, H. H. (2015.): Culture of living together in the context of humannature dialectic. - Academic Overview International Refereed Journal of Social Science 52: 64-78 (in Turkish).

[43] Karadağ, A. A. (2019): A Research on determination of vulnerable landscapes in terms of groundwater: Duzce case, Turkey. - Fresenius Environmental Bulletin 28(4A): 32313241.

[44] Kesoretskikh, I., Zotov, S, Drobiz, M. (2015): Assessing spatial and temporal changes in the landscape vulnerability in the Kaliningrad Region as an element of sustainable spatial planning. - Baltic Region 4(26): 122-136.

[45] Knox, J. C. (2001): Agricultural influence on landscape sensitivity in the upper Mississippi river valley. - Catena 42: 193-224.

[46] Kocabaş, S., Çelik, F., Aksoy, Ö., Kiriş, C. (2016): Landslide Sensitivity Analysis Report. - Düzce Provincial Directorate of Disaster and Emergency, Düzce, Türkiye (in Turkish).

[47] Kosydar, A. J., Conquest, L. L., Tewksbury, J. J. (2014): Can life histories predict the effects of habitat fragmentation? A meta-analysis with terrestrial mammals. - Applied Ecology and Environmental Research 12(2): 505-521.

[48] Lewis, S. L., Maslin, M. A. (2015): Defining the anthropocene. - Nature 519(7542): 171180.

[49] Mazzino, F., Burlando, P. (2010): Cultural landscapes: negotiation between global and local. - A-Z ITU Journal of the Faculty of Architecture 7(2): 14-20.

[50] Menezes, J. A., Confalonieri, U., Madureira, A. P., Duval, I. B., Santos, R. B. D. (2018): Mapping human vulnerability to climate change in the Brazilian Amazon: the construction of a municipal vulnerability Index. - PLoS One 13(2): 1-30.

[51] Miles, J., Cummins, R. P., French, D. D., Fardner, S., Orr, J. L. (2001): Landscape sensitivity: an ecological view. - Catena 42: 125-141.

[52] Mingwu, Z., Haijiang, J., Desuo, C., Chunbo, J. (2010): The comparative study on the ecological sensitivity analysis in Huixian karst wetland, China. - Procedia Environmental Sciences 2: 386-398.

[53] Özaslan, M., Erşahin, G., Akkahve, D., Sabuncu, A. (2001): Duzce Province Report. State Planning Organization General Directorate of Regional Development, Ankara, Turkey.

[54] Penghua, Q., Songjun, X., Genzong, X., Benan, T., Hua, B., Longshi, Y. (2007): Analysis of the ecological vulnerability of the Western Hainan Island based on its landscape pattern and ecosystem sensitivity. - Acta Ecologica Sinica 27(4): 1257-1264.

[55] Phillips, J. D. (1999): Earth Surface Systems. - Blackwell Publishers Ltd, Oxford, UK.

[56] Rempel, R. (2010): Centre for Northern Forest Ecosystem Research. - www. www.flash.lakeheadu.ca/ rrempel/ecology/papers/patchanalyst.pdf (date of access: 12.04.2019).

[57] Saran, E., Dusza Zwolıńska, E., Gamrat, R. (2019): Plant species richness in fragmented agricultural landscape-meta-analysis. - Applied Ecology and Environmental Research 17(1): 53-83.

[58] Shi, S. X., Tong, P. S. (2019): Evaluation system and spatial distribution pattern of ecological city construction-based on dpsir-topsis model. - Applied Ecology and Environmental Research 171: 601-616.

[59] Shi, Y., Lib, J., Xie, M. (2018): Evaluation of the ecological sensitivity and security of tidal flats in Shangha1. - Ecological Indicators 85: 729-741.

[60] Steffen, W., Grinevald, J., Crutzen, P., McNeill, J. (2011): The anthropocene: conceptual and historical perspectives. - Mathematical, Physical and Engineering Sciences 369(1938): 842-867.

[61] Tatar, Y. (2003): Duzce Province Development Plan: Environment and Spatial Development. - www.duzce.edu.tr (date of access: 23.01.2019) (In Turkish). 
[62] Thomas, M. F. (2001): Landscape sensitivity in time and space - an introduction. Catena 42: 83-98.

[63] Turner, M. G., Gardner, R. H., O’Neill, R. V. (2001): Landscape Ecology in Theory and Practice. - New York: Springer-Verlag.

[64] Turner II, B. L., Kasperson, R. E., Matson, P. A., Mc Carthy, J. J., Corell, R. W., Christensen, L., Eckley, N., Kasperson, J. X., Luers, A., Martello, M. L., Polsky, C., Pulsipher, A., Schiller, A. (2003): A framework for vulnerability analysis in sustainability science. - Proceedings of the National Academy of Sciences of the United States of America 100(14): 8074-8079.

[65] Turner, S. (2018): Historic Landscape Characterisation. - In: Fairclough, G., Sarlöv Herlin, I., Swanwick, C. (eds.) Routledge Handbook of Landscape Character Assessment Current Approaches to Characterisation and Assessment. Routledge, Abingdon. www.routledge.com (date of access: 13.03.2019).

[66] Usher, M. B. (2001): Landscape sensitivity: from theory to practice. - Catena 42: 375383.

[67] Uzun, O., İlke, E. F., Cetinkaya, G., Erduran, F., Ac1ksoz, S. (2012): Landscape Planning: Bozkir-Seydisehir-Ahirli-Yalihüyük District of Konya and Sugla Lake Village Landscape Management Conservation and Planning Project. - The Ministry of Forestry and Water Affairs, Ankara, Turkey (in Turkish).

[68] Uzun, O., Muderrisoglu, H., Demir, Z., Kaya, L., G., Gultekin, P., Gunduz, S. (2015): Yesilirmak Basin Landscape Atlas Project (II. Report). - The Ministry of Forestry and Water Affairs, Ankara, Turkey (in Turkish).

[69] Vaillant, N. M., Kolden, C. A., Smith, A. M. S. (2010): Assessing landscape vulnerability to wildfire in the USA. - Current Forestry Reports 23: 201-213.

[70] Walker, L. R., Shiels, A. B. (2013): Landslide Ecology. - Cambridge University Press, New York.

[71] Wang, X., Bian, Z. (2011): The implications of ecological sensitivity on exploitation of unutilized land: a case study in Ji'Nan City, China. - Procedia Environmental Sciences 10: $275-281$. 